\title{
Pemetaan Daerah Rawan Longsor di Kecamatan Banyumanik, Kota Semarang
}

\author{
Taqorrub Ubaidillah \\ Institut Agama Islam Negeri Ponorogo, Ponorogo, Indonesia \\ taqorrub@gmail.com \\ Nastiti Mufidah \\ Institut Agama Islam Negeri Ponorogo, Ponorogo, Indonesia \\ nastiti@iainponorogo.ac.id
}

\begin{abstract}
The research was done in Banyumanik Sub-district, Semarang City, Central Java Province. The purposes of the research were to know terrain unit and landslide suceptibility in the research area. Unit of analysis in this research was terrain unit which obtained from overlay between landform, geology, slope, and soil maps. The overlay result is 147 terrain units in the research area. Sampling technique use stratified random sampling to select sample based strata. 19 samples are selected from 147 terrain units. Method of collecting data use survey method to obtain primary data and documentation method to obtain secondary data. Technique of data analysis use wight method for 6 parameters. The parameters are land use, soil tecture, rock layering structure, rainfall, soil permeability and slope. Research results show that landslide susceptibility in the research area was classified in 5 susceptibility classes i.e. very low class cover area of 0,6 km2 (0,19\%), low class cover area of 7,24 km2 (23,59\%), moderate class cover area of 7,16 km2 (23,33\%), high class cover area of $12,35 \mathrm{~km} 2(40,24 \%)$, and very high class cover area of $3,88 \mathrm{~km} 2(12,64 \%)$.
\end{abstract}

Keywords: Landslide; Susceptibility; Terrain Unit; Banyumanik; SubDistrict; Semarang City 


\begin{abstract}
Abstrak
Penelitian ini dilakukan di daerah Kecamatan Banyumanik Kota Semarang Provinsi Jawa Tengah. Tujuan utama di dalam penelitian yakni untuk mengetahui satuan medan dan mengetahui tingkat kerawanan longsor di daerah penelitian. Unit analisis satuan medan digunakan dalam penelitian ini yang diperoleh dari tumpangsusun (overlay) peta bentuklahan, geologi, kemiringan lereng, dan jenis tanah sehingga menghasilkan 147 satuan medan di daerah penelitian. Teknik sampling yang digunakan adalah stratified random sampling yaitu setiap medan dikelompokkan menjadi populasi yang relatif homogen, kemudian diambil sampel secara acak sehingga diperoleh 19 sampel. Data primer dalam penelitian ini diperoleh dengan menggunakan metode survei lapangan, sedangkan dara skunder diperoleh dengan metode dokumentasi. Teknik analisis data menggunakan metode pembobotan 6 parameter yaitu penggunaan lahan, tekstur tanah, struktur perlapisan batuan, curah hujan, permeabilitas tanah dan kelas kemiringan lereng. Hasil penelitian menunjukkan tingkat kerawanan longsor di daerah penelitian terbagi kedalam 5 kelas kerawanan yaitu kelas kerawanan sangat rendah mencakup daerah seluas $0,6 \mathrm{~km} 2(0,19 \%)$, kelas kerawanan rendah mencakup daerah seluas $7,24 \mathrm{~km} 2(23,59 \%)$, kelas kerawanan sedang mencakup daerah seluas $7,16 \mathrm{~km} 2(23,33 \%)$, kelas kerawanan tinggi mencakup daerah seluas $12,35 \mathrm{~km} 2(40,24 \%)$, dan kelas kerawanan sangat tinggi mencakup daerah seluas 3,88 km2 (12,64\%).
\end{abstract}

Kata kunci: Kerawanan; Longsor; Satuan Medan; Kecamatan Banyumanik; Kota Semarang

\title{
A. Pendahuluan
}

Indonesia khususnya di kota-kota besar dari tahun ketahun pertumbuhan penduduknya kian meningkat, tak terkecuali di Kota Semarang. Pertumbuhan tersebut disinyalir meningkatkan konsekuensi akan kebutuhan hidup baik kebutuhan primer maupun skunder. Pemenuhan akan kebutuhan primer, khususnya kebutuhan papan mengharuskan adanya pembukaan lahan baru guna dijadikan pemukiman Kota Semarang menjadi salah satu kota yang menjadi pusat perdagangan dan industri di Jawa Tengah. Sebagai salah satu kota yang memberikan sumbangsih yang cukup besar akan kemajuan perekonomian dan bisnis, Kota Semarang tak luput dari aktivitas-aktivitas yang disinyalir berpengaruh negatif akan kondisi lingkungannya. Pengaruh tersebut mengakibatkan munculnya degradasi lingkungan yang tak dapat dihindari, sehingga kerapkali mengakibatkan berbagai bencana alam seperti banjir, instrusi air laut, gempa bumi maupun longsor.

Salah satu bencana alam yang kerapkali menjadi permasalahan yang yakni bencana longsor (Virgiawan 2020). Di Jawa bencana longsor menjadi permasalahan 
kompleks yang selalu mengalami peningkatan dari tahun ketahun (Hadmoko D.S., Lavigne F., Sartohadi J., Hadi P. 2010). Berbagai kerusakan seperti jalan, irigasi, pemukiman, lahan pertanian serta bebagai sarana dan prasana merupaka dampak lain yang diakibatkan oleh bencana longsor selain dari timbulnya korban jiwa (Priyono K.D., Priyana Y. 2006). Dikarenakan frekuensi kejadian longsor yang tinggi di jawa dan tingkat kerentanan penduduk yang tinggi maka tidak heran jika kematian yang diakibatkan oleh longsor di pulau Jawa sangatlah tinggi.

Kondisi topografi di Kota Semarang saat ini relatif landai sampai berbukit dengan kepadatan penduduk tinggi, hal tersebut diakibatkan oleh pertumbuhan penduduk di kota tersebut kian meningkat setiap tahunnya. Kota Semarang juga tak luput dari berbagai bencana alam seperti banjir, instrusi air laut, gempa bumi, longsor, rob serta angin puting beliung. Namun, bencana yang kerapkali terjadi di Kota Semarang adalah bencana longsor.

Kecamatan Banyumanik adalah salah satu dari beberapa kecamatan yang berlokasi di Kota Semarang, Provinsi Jawa Tengah. Kecamatan tersebut berlokasi di area yang mendapat sebutan sebagai kota atas Semarang. Sebutan tersebut disematkan karena Kecamatan Banyumanik berlokasi di ketinggian sekitar 300 meter di atas permukaan laut, dengan suhu udara rata-rata $20-22^{\circ}$ C. Luas wilayah Kecamatan Banyumanik adalah 25,13 km² dengan jumlah penduduk 135.689 jiwa (tahun 2016) dengan kepadatan penduduk 5.399,48 jiwa/ $\mathrm{km}^{2}$ (BPS 2016).

Tabel 1. Kejadian Longsor Kecamatan Banyumanik 8 Tahun Terakhir

\begin{tabular}{llllc}
\hline No & $\begin{array}{c}\text { Tanggal } \\
\text { Kejadian }\end{array}$ & Kelurahan & Kerusakan & $\begin{array}{c}\text { Korban } \\
\text { Jiwa }\end{array}$ \\
\hline 1 & 8 & Ngesrep & Talud & $\begin{array}{c}\text { 2 Orang } \\
\text { meninggal }\end{array}$ \\
& November & & & \\
& 2011 & & & - \\
2 & 7 Januari & Jalan Jangli & Jalan tol & - \\
\hline & 2012 & & & \\
3 & 18 Januari & Tinjomoyo & 4 Rumah & - \\
& 2012 & & & \\
4 & 12 & Pudakpayung & 2 Rumah & \\
& November & & & \\
& 2013 & &
\end{tabular}




\begin{tabular}{|c|c|c|c|c|}
\hline 5 & $\begin{array}{l}4 \text { Februari } \\
2014\end{array}$ & Tinjomoyo & 1 Rumah & $\begin{array}{l}1 \text { Orang } \\
\text { meninggal }\end{array}$ \\
\hline 6 & $\begin{array}{l}25 \text { Maret } \\
2015\end{array}$ & Jabungan & Jalan aspal & - \\
\hline 7 & $\begin{array}{l}8 \text { Januari } \\
2016\end{array}$ & Pudakpayung & $\begin{array}{l}1 \text { Pagar } \\
\text { rumah }\end{array}$ & - \\
\hline 8 & $\begin{array}{l}3 \text { Oktober } \\
2016\end{array}$ & Ngesrep & 1 Rumah & $\begin{array}{l}2 \text { Orang } \\
\text { meninggal }\end{array}$ \\
\hline 9 & $\begin{array}{l}26 \text { Januari } \\
2017\end{array}$ & Gedawang & 1 Rumah & - \\
\hline 10 & $\begin{array}{l}13 \\
\text { Februari } \\
2017\end{array}$ & Pudakpayung & - & $\begin{array}{l}1 \text { Orang } \\
\text { luka-luka }\end{array}$ \\
\hline 11 & $\begin{array}{l}24 \\
\text { Februari } \\
2017\end{array}$ & Tinjomoyo & Talud & - \\
\hline 12 & $\begin{array}{l}13 \text { Juli } \\
2017\end{array}$ & Pudakpayung & 1 Rumah & - \\
\hline 13 & $\begin{array}{l}10 \\
\text { Februari }\end{array}$ & Gedawang & 1 Rumah & - \\
\hline 14 & $\begin{array}{l}2018 \\
10 \text { Maret } \\
2018\end{array}$ & Pudakpayung & 1 Rumah & - \\
\hline 15 & $\begin{array}{l}18 \text { April } \\
2018\end{array}$ & Tinjomoyo & 3 Rumah & - \\
\hline 16 & $\begin{array}{l}8 \\
\text { Desember } \\
2018\end{array}$ & $\begin{array}{l}\text { Srondol } \\
\text { Wetan }\end{array}$ & 1 Rumah & - \\
\hline
\end{tabular}

Sumber: BPBD Kota Semarang 2018 
Berdasarkan Peta Geologi Lembar Magelang-Semarang, Jawa, daerah Banyumanik disusun oleh formasi damar, yang tersusun dari batu pasir tufaan, konglomerat, dan breksi volkanik (Thanden R, E., Sumadhirda H., Richards, P, W., Sutrisna K. 2006). Menurut Badan Geologi, Pusat Volkanologi dan Mitigasi Bencana Geologi (BPS 2016) menyatakan bahwa Kecamatan Banyumanik termasuk kedalam zona yang berpotensi terjadi gerakan tanah menengah-tinggi. Pernyataan tersebut mengandung artian bahwa di dalam zona tersebut apabila curah hujan diatas normal maka rentan terjadi gerakan tanah. Tingkat kerentanan akan semakin tinggi apabila hal tersebut terjadi di daerah yang berbatasan langsung dengan lembah sungai, gawir, tebing jalan atau jika lereng mengalami gangguan (Trisnawati et al. 2020). Curah hujan yang tinggi pada daerah tersebut dapat pula mengaktifkan gerakan tanah yang lama.

Dari penjelasan tersebut maka perlu dilakukan suatu penelitian dengan melakukan analisis tingkat kerawanan longsor. Hal tersebut merupakan upaya mitigasi bencana longsor serta sebagai dasar dalam merencanakan penggunaan atau pemanfaatan lahan di daerah penelitian. Bersadarkan uraian latar belakang dan permasalahan yang telah dideskripsikan dimuka, maka tujuan penelitian ini yakni, mengetahui tingkat satuan medan di daerah penelitian serta mengetahui tingkat kerawanan longsor yang berada di daerah penelitian.

\section{B. Pembahasan}

Satuan medan digunakan sebagai unit analisis dalam penelitian ini. Dikarenakan populasi dalam penelitian ini relatif heterogen, maka pengambilan atau pengukuran karakteristik medan dilakukan dengan cara stratified random sampling. Menurut Supranto stratified random sampling adalah sampling dimana sampelnya diperoleh dengan cara: 1. Popolasi dipecah atau dibagi, 2. Pembentukan tratum harus homogen atau relating homogeny, 3. Setiap stratum diambel sampel secara acak yang dapat mewakili, 4. Perkiraan secara menyeluruh yang diperoleh secara gabungan (Suprapto J, 2007).

Variabel atau faktor yang digunakan dalam pemetaan longsor diturunkan dari faktor yang diyakini sebagai penyebab terjadinya longsor. Dalam penelitian ini digunakan 5 variabel longsor yang meliputi: (1) bentuklahan (2) curah hujan (3) struktur geologi (4) tanah (5) penggunaan lahan.

Metode survei lapangan dan metode dokumentasi digunakan dalam pengumpulan data. Metode survei lapangan digunakan untuk mendapatkan data primer yang dalam hal ini adalah data lapangan secara langsung yang meliputi pengukuran, pengamanatan kondisi fisik medan, dan check lapangan untuk mencocokkan kondisi di peta dengan keadaan di lapangan. Metode dokumentasi digunakan untuk mendapatkan 
data sekunder yang dalam hal ini berupa data curah hujan, jenis tanah, penggunaan lahan, struktur geologi yang bersumber dari instansi pemerintah Kota Semarang.

Satuan medan dengan menggunakan teknik pembobotan di setiap ukuran satuan medan yang diteliti digunakan sebagai unit analisis dalam menentukan tingkat kerawanan longsor. Satuan medan adalah satuan pemetaan terkecil dan dapat dibuat melalui overlay dengan menggunakan teknologi Sistem Informasi Geografis (SIG) dari beberapa peta, yaitu peta kemiringan lereng, peta bentuklahan, peta geologi, dan peta jenis tanah. Setiap parameter diberi harkat, yaitu harkat minimum adalah 1 dan harkat maksimum adalah 5. Adapun 5 parameter yang digunakan sebagai penentu tingkat kerawanan longsor yaitu: tekstur tanah, struktur perlapisan batuan, curah hujan, kemiringan lereng, dan penggunaan lahan.

Selanjutnya ditentukan kelas kerawanan longsor sebagai berikut:

Jumlah parameter yang digunakan

Jumlah harkat terendah (1) dari 5 parameter

Jumlah harkat tertinggi (5) dari 5 parameter
5 Parameter $(\mathrm{A})$

5

25

Besar kelas interval (I) berdasarkan metode yang digunakan adalah (Dibyosaputro, 1999):

$$
\begin{gathered}
I=\frac{C-B}{A} \\
I=\frac{25-5}{5} \\
I=\frac{20}{5}=4
\end{gathered}
$$

Keterangan:

I : Besar kelas interval

$B \quad$ : Jumlah harkat terendah

C : Jumlah harkat tertinggi

A : Jumlah kelas yang diinginkan (5 kelas)

Berdasarkan persamaan di atas maka besar kelas interval masing-masing adalah: 
Tabel 2. Klasifikasi Tingkat Kerawanan Longsor

\begin{tabular}{ccl}
\hline No & Kelas Interval & \multicolumn{1}{c}{ Tingkat Kerawanan Longsor } \\
\hline 1 & $6-10$ & Sangat rendah \\
2 & $11-15$ & Rendah \\
3 & $16-20$ & Sedang \\
4 & $21-25$ & Tinggi \\
5 & $26-30$ & Sangat tinggi \\
\hline
\end{tabular}

\section{Kondisi Fisik Daerah Penelitian}

Kecamatan Banyumanik terletak di Kota Semarang Provinsi Jawa Tengah. Berdasarkan Peta Rupa Bumi Indonesia skala 1:25.000 lembar Jatingaleh daerah penelitian terletak pada koordinat geografis antara $7^{0} 01^{\prime} 30^{\prime \prime} \mathrm{LS}-7^{0} 06^{\prime} 00^{\prime \prime}$ LS dan $110^{\circ} 24^{\prime} 00^{\prime}$ ' BT $-110^{\circ} 27^{\prime} 00^{\prime}$ ' BT atau pada koordinat UTM zona $49 \mathrm{M}$ antara $434000 \mathrm{mT}$ - $440000 \mathrm{mT}$ dan $9214000 \mathrm{mU}$ - $9223000 \mathrm{mU}$. Luas daerah penelitian adalah $30,74 \mathrm{~km}^{2}$ atau 3074 hektar. Daerah penelitian secara administratif berbatasan dengan: Kecamatan Candisari dan Kecamatan Gajahmungkur di sebelah utara, berbatasan dengan Kecamatan Tembalang di sebelah timur, berbatasan dengan Kecamatan Gunungpati di sebelah barat, dan berbatasan dengan Kabupaten Semarang di sebelah selatan.

Kondisi tanah di daerah penelitian bervariasi. Terdapat 8 jenis tanah (sub group) yang tersebar di daerah penelitian, diantaranya adalah Inceptisol (aeric tropaquept, andic dystrudept, oxic dystrudept, typic dystrudept), Vertisol (typic hapludert), Ultisol (typic hapludult), dan Entisol (typic ustorthent, vertic ustorthent). Jenis tanah yang paling dominan adalah Typic Hapludult dengan luas sebesar 17,65 km2 atau 57,90\%.

Menurut Thanden dkk. dalam Peta Geoogi Lembar Semarang-Magelang skala 1:100.000, Kecamatan Banyumanik tersusun atas 4 formasi geologi, diantaranya Aluvium (Qa) yang mana merupakan dataran pantai, sungai dan danau. Formasi Damar (QTd) terdiri dari batupasir tufan, konglomerat, breksi vulkanik. Formasi Kaligetas (Qpkg) terdiri breksi vulkanik, aliran lava, tuf, batupasir tufan dan batulempung. Formasi Kerek (Tmk) terdiri dari perselingan batulempung, napal, batupasir tufan, konglomerat, breksi vulkanik dan batugamping (Thanden R, E., Sumadhirda H., Richards, P, W., Sutrisna K. 2006).

Bentuklahan di daerah penelitian secara genesis terdiri dari 3 bentuklahan, diantaranya bentuklahan asal proses fluvial (F), bentuklahan asal proses struktural (S), 
dan bentuklahan asal proses denudasional (D). Bentuklahan asal proses fluvial di daerah penelitian terdiri dari dataran alluvial (F1) dan tanggul alam (F8). Bentuklahan ini terjadi akibat pengaruh sungai yang berupa proses pengaliran, pengangkutan, dan pengendapan. Bentuklahan asal proses struktural di daerah penelitian terdiri dari gawir sesar (S2). Bentuklahan ini terjadi sebagai akibat pengaruh tenaga endogen yang berupa tektonisme. Karakteristik bentuklahan struktural adalah adanya sesar dan lipatan pada suatu daerah. Bentuklahan asal proses denudasional di daerah penelitian terdiri dari perbukitan terkikis (D1) dan bukit terisolasi (D4). Bentuklahan ini terjadi akibat proses pengikisan dan pelapukan. Karakteristik bentuklahan denudasional adalah terdapat bekas longsoran di suatu daerah dan umumnya banyak ditemukan batuan dengan umur tersier.

Kondisi topografi di daerah penelitian relatif beragam. Berdasarkan survei lapangan, topografi datar-landai banyak dijumpai di bagian tengah daerah penelitian. Umumnya topografi ini dimanfaatkan untuk permukiman penduduk. Topografi berombak-bebukit banyak ditemukan di sebelah utara dan selatan daerah penelitian. Umumnya topografi ini dimanfaatkan untuk kebun, tegalan, dan sawah. Topografi berbukit-bergunung banyak ditemukan di sebelah barat daerah penelitian, yakni letaknya berada disepanjang sungai garang. Umumnya topografi ini dimanfaatkan untuk hutan dan kebun.

Kemiringan lereng di daerah penelitian terdiri atas lereng datar (0-8\%), landai (8-15\%), agak curam (15-25\%) dan curam (25-45\%). Lereng datar di daerah penelitian seluas $8,74 \mathrm{~km}^{2}$ atau $28,48 \%$ dari total luas daerah penelitian. Lereng landai mempunyai luas $8,62 \mathrm{~km}^{2}$ atau $28,09 \%$ dari seluruh luas daerah penelitian. Lereng agak curam memiliki luas $6,74 \mathrm{~km}^{2}$ atau $21,96 \%$ dari total luas daerah penelitian. Lereng curam mempunyai luas $6,6 \mathrm{~km}$ atau $21,50 \%$ dari total luas daerah penelitian.

Menurut data curah hujan BAPPEDA Kota Semarang (Bappeda Kota Semarang 2011) kondisi curah hujan di daerah penelitian cukup bervariasi yakni terdiri dari curah hujan 1000-1500 mm/tahun atau masuk dalam kategori rendah yang mencakup daerah seluas $4,17 \mathrm{~km}^{2}$ atau $13,59 \%$ dari total luas daerah penelitian. Curah hujan 1500-2000 $\mathrm{mm} /$ tahun atau masuk dalam kategori sedang yang mencakup daerah seluas $12,5 \mathrm{~km}^{2}$ atau $40,73 \%$ dari total luas daerah penelitian. Curah hujan 2000-2500 mm/tahun atau masuk dalam kategori tinggi yang mencakup daerah seluas $14,02 \mathrm{~km}^{2}$ atau $45 \%$ dari total luas daerah penelitian.

Kondisi curah hujan yang bervariasi di daerah penelitian dipengaruhi oleh ketinggian tempat dan tutupan vegetasi. Curah hujan rendah di daerah penelitian umumnya mempunyai ketinggian tempat antara 100-150 meter Diatas Permukaan Air 
Laut (DPAL). Penggunaan lahan banyak di dominasi oleh permukiman penduduk dan sedikit vegetasi. Curah hujan sedang umumnya mempunyai ketinggian tempat antara 150-250 meter DPAL. Penggunaan lahan sebagian terdiri dari permukiman dan kebun campuran. Curah hujan tinggi umumnya mempunyai ketinggian tempat antara 250-350 meter DPAL dan penggunaan lahan banyak didominasi oleh kebun dan hutan.

Penggunaan lahan di daerah penelitian terdiri dari tubuh air $\left(0,15 \mathrm{~km}^{2}\right)$, belukar/semak $\left(4,32 \mathrm{~km}^{2}\right)$, gedung $\left(0,03 \mathrm{~km}^{2}\right)$, permukiman $\left(10,57 \mathrm{~km}^{2}\right)$, kebun $(6,87$ $\left.\mathrm{km}^{2}\right)$, sawah irigasi $\left(1,71 \mathrm{~km}^{2}\right)$, sawah tadah hujan $\left(0,23 \mathrm{~km}^{2}\right)$, tegalan $\left(5,77 \mathrm{~km}^{2}\right)$, dan rumput $\left(1,06 \mathrm{~km}^{2}\right)$. Penggunaan lahan di daerah penelitian di dominasi oleh permukiman dengan luas $10,57 \mathrm{~km}^{2}$ atau 1057 hektar dengan persentase $34,44 \%$ dari total luas daerah penelitian. Penggunaan lahan paling kecil di daerah penelitian adalah gedung yakni menempati lahan seluas $0,03 \mathrm{~km}^{2}$ dengan persentase $0,10 \%$ dari total luas daerah penelitian.

Penggunaan lahan untuk permukiman tersebar di bagian tengah daerah penelitian. Penggunaan lahan ini berdampingan dengan penggunaan lahan untuk gedung, rumput, tegalan dan kebun. Penggunaan lahan untuk belukar/semak tersebar tidak merata, yakni berada di bagian barat disepanjang pinggir sungai garang, dibagian selatan, dan di utara daerah penelitian. Penggunaan lahan ini berdampingan dengan tubuh air, sawah tadah hujan, dan sawah irigasi.

\section{Tingkat Kerawanan Longsor}

Tingkat kerawanan longsor di daerah penelitian dihitung dengan menggunakan teknik pembobotan pada 5 parameter, yaitu parameter kemiringan lereng, penggunaan lahan, tekstur tanah, struktur perlapisan batuan, dan curah hujan. Masing-masing parameter diberi skor 1 sampai 5 kemudian dilakukan overlay sehingga menghasilkan tingkat kerawanan longsor di daerah penelitian yang meliputi 5 kategori yaitu sangat rendah yang mencakup daerah seluas $0,6 \mathrm{~km}^{2}$, kategori rendah mencakup daerah seluas $7,24 \mathrm{~km}^{2}$, kategori sedang mencakup daerah seluas $7,16 \mathrm{~km}^{2}$, kategori tinggi mencakup daerah seluas $12,35 \mathrm{~km}^{2}$, dan kategori sangat tinggi mencakup daerah seluas $3,88 \mathrm{~km}^{2}$. 
Tabel 3. Tingkat Kerawanan Longsor di Daerah Penelitian

\begin{tabular}{|c|c|c|c|}
\hline No & $\begin{array}{c}\text { Tingkat } \\
\text { Kerawanan } \\
\text { Longsor }\end{array}$ & $\begin{array}{l}\text { Luas } \\
\left(\mathrm{km}^{2}\right)\end{array}$ & $\begin{array}{c}\text { Persentase } \\
(\%)\end{array}$ \\
\hline 1 & $\begin{array}{l}\text { Sangat } \\
\text { Rendah }\end{array}$ & 0.06 & 0,19 \\
\hline 2 & Rendah & 7,24 & 23,59 \\
\hline 3 & Sedang & 7,16 & 23,33 \\
\hline 4 & Tinggi & 12,35 & 40,24 \\
\hline 5 & Sangat Tinggi & 3,88 & 12,64 \\
\hline
\end{tabular}

Sumber: Analisis Peta Kerawanan Longsor 2020

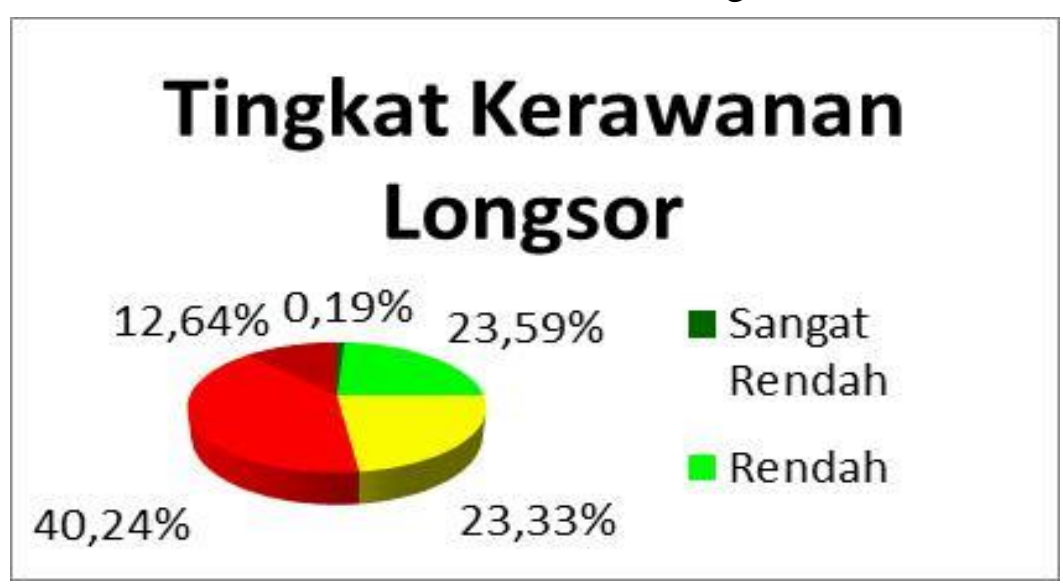

Gambar 1. Grafik Kerawanan Longsor di Daerah Penelitian 


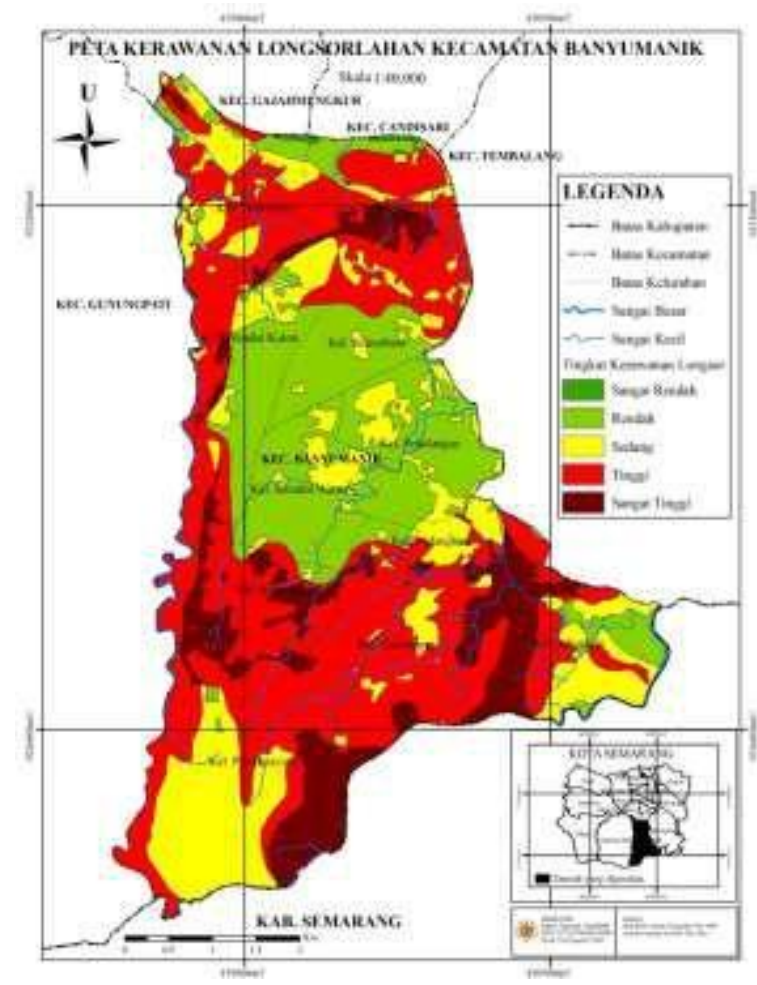

Gambar 2. Peta Kerawanan Longsor di Daerah Penelitian

\section{Agihan Tingkat Kerawanan Medan terhadap Longsor}

Dari hasil peta rawan longsor yang diperoleh dapat di identifikasi karakteristik wilayah berdasarkan faktor yang membentuk rawan longsor. Untuk masing-masing kelas kerawanan longsor sebagai berikut:

1. Tingkat kerawanan sangat rendah ditemukan pada bentuklahan F1 (dataran alluvial) dengan lereng kelas I (0-8\%), khususnya pada tanah Typic Hapludult. Penggunaan lahan sebagian besar berupa gedung dan permukiman. Curah hujan rata-rata 1000-1500 mm/tahun. Ketinggian tempat/elevasi bervariasi antara 25-65 meter DPAL dan 65-105 meter DPAL.

2. Tingkat kerawanan rendah banyak ditemukan pada bentuklahan D1 (perbukitan terkikis) dengan kelas lereng I dan kelas II, khususnya pada tanah Typic Hapludult dan Typic Hapludert. Penggunaan lahan berupa sawah, tegalan, belukar, kebun campuran dan permukiman, dimana permukiman merupakan penggunaan lahan yang sangat dominan. Curah hujan sebagian besar rata-rata berkisar antara 1000-1500 mm/tahun. Elevasi bervariasi antara 65-105 meter DPAL dan 105-145 meter DPAL.

3. Tingkat kerawanan sedang banyak ditemukan pada bentuklahan S2 (Gawir Sesar) dengan kelas lereng II dan III, khususnya pada tanah Oxic 
Dystrudept dan Aeric Tropaquept. Penggunaan lahan sebagian besar berupa kebun campuran dan sawah. Curah hujan berkisar antara 1500-2000 $\mathrm{mm} /$ tahun. Ketinggian tempat sebagian besar antara 145-186 meter DPAL dan 186-226 meter DPAL.

4. Tingkat kerawanan tinggi adalah area yang paling luas di daerah penelitian yaitu mencakup daerah seluas $12,35 \mathrm{~km}^{2}$, kategori ini banyak ditemukan pada bentuklahan D4 dan F8 dengan kelas lereng III dan IV, khususnya pada jenis tanah Typic Dystrudept dan Typic Hapludult. Penggunaan lahan pada kategori ini didominasi oleh kebun campuran, tegalan, hutan, dan sebagian kecil permukiman. Curah hujan tahunan di area ini berkisar antara 2000-2500 $\mathrm{mm} /$ tahun. Evelasi atau ketinggian tempat bervariasi antara 226-266 meter DPAL dan 266-306 meter DPAL.

Tingkat kerawanan sangat tinggi banyak ditemukan pada bentuklahan D1 dan S2 dengan kelas lereng IV, khususnya pada tanah Typic Hapludult. Jenis penggunaan lahan pada ketori ini didominasi oleh sawah, tegalan, hutan, kebun campuran, dan sedikit permukiman. Curah hujan rata-rata per tahun berkisar antara 2000-2500 mm/tahun. Ketinggian tempat bervariasi antara 306-347 meter DPAL dan 347-387 meter DPAL.

\section{Pola Spasial Agihan Tingkat Kerawanan Longsor}

Analisis keruangan adalah analisis lokasi yang menitikberatkan pada tiga unsur yaitu jarak (distance), kaitan/hubungan yang saling mempengaruhi (interaction), dan gerakan (movement) (Kusnadi, 2010). Tujuan dari analisis keruangan adalah untuk mengukur apakah kondisi yang ada sesuai dengan struktur keruangan, dan menganalisa antar unit keruangan, yaitu hubungan antara ekonomi dan interaksi keruangan, aksesiblitas antara pusat dan perhentian suatu wilayah, dan hambatan interaksi, hal ini didasarkan oleh adanya tempat-tempat yang menjadi pusat kegiatan bagi tempat-tempat lain, serta adanya hirarki diantara tempat-tempat tersebut. 
Tabel 4. Keterkaitan Penggunaan Lahan pada Daerah Rawan Longsor

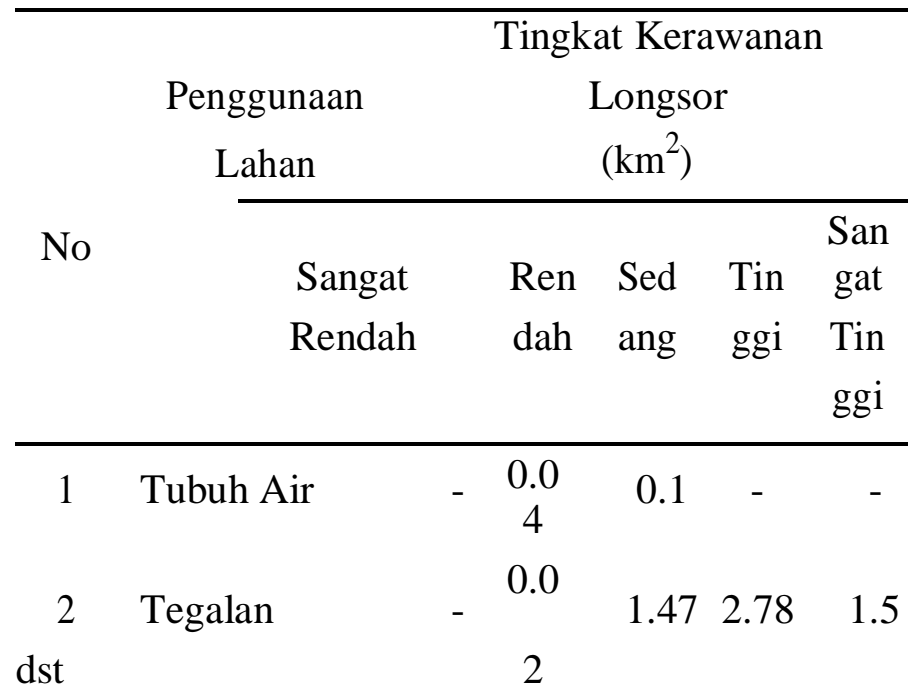

Sumber: Analisis Spasial ArcGIS 2020

Pola sebaran daerah rawan longsor di daerah penelitian berdasarkan peta kerawanan longsor yang disajikan pada Gambar 2 membentuk pola menyebar dan mengumpul. Pola menyebar terdiri dari kelas kerawanan longsor sedang, tinggi, sangat tinggi, dan sangat rendah. Umumnya pola ini terbentuk karena penggunaan lahan yang bervariasi (rumput, tegalan, kebun, sawah, dl) dengan kelas lereng yang beragam mulai kelas II (8-15\%) hingga kelas IV (25-45\%). Sedangkan pola mengumpul terdiri dari kelas kerawanan rendah dan sedang yang terdapat dibagian tengah daerah penelitian. Umumnya pola ini terbentuk karena penggunaan lahan di dominasi oleh permukiman dengan kelas lereng I (0-8\%).

Keterkaitan penggunaan lahan pada daerah rawan longsor yang disajikan pada Tabel 4 berhubungan dengan kelas lereng dimana lahan tersebut digunakan. Tubuh air dengan luas area sebesar $0.15 \mathrm{~km}^{2}$ terdapat pada kelas kerawanan longsor rendah dan sedang. Belukar/semak dengan luas area sebesar $4.32 \mathrm{~km}^{2}$ terdapat pada kelas kerawanan longsor sedang, tinggi, dan sangat tinggi. Kondisi tersebut terjadi karena sebagian besar penggunaan lahan belukar/semak terdapat pada kelas lereng curam hingga terjal di daerah penelitian. Gedung dengan luas area sebesar $0.03 \mathrm{~km}^{2}$ terdapat pada kelas kerawanan longsor rendah, sedang, tinggi. Gedung dengan luas area yang kecil dapat menempati kelas kerawanan tinggi karena mungkin saat melakukan pembangunan gedung kurang begitu memperhatikan lingkungan seperti daerah dengan lereng curam dan kondisi tanah yang labil.

Permukiman penduduk dengan luas area sebesar $10.57 \mathrm{~km}^{2}$ terdapat pada kelas kerawanan longsor rendah, sedang, tinggi dan sangat tinggi. Umumnya permukiman 
dengan kelas kerawanan rendah $\left(4.83 \mathrm{~km}^{2}\right)$ dan sedang $\left(2.43 \mathrm{~km}^{2}\right)$ banyak dijumpai pada lereng datar hingga landai di daerah penelitian. Sedangkan penggunaan lahan untuk permukiman dengan kelas kerawanan tinggi $\left(3.29 \mathrm{~km}^{2}\right)$ dan sangat tinggi $(0.02$ $\mathrm{km}^{2}$ ) disebabkan karena banyaknya jumlah penduduk sebesar 127,287 jiwa dan luas area kecamatan sebesar $30,74 \mathrm{~km}^{2}$ dengan kepadatan penduduk 4,955 jiwa per $\mathrm{km}^{2}$ memaksa penduduk untuk membangun permukiman di daerah yang sebenarnya tidak layak untuk dijadikan tempat tinggal, seperti area dengan kelas lereng III dan IV.

Kebun dengan luas area $6.87 \mathrm{~km}^{2}$ terdapat pada kelas kerawanan longsor rendah, sedang, tinggi, dan sangat tinggi. Penggunaan lahan untuk kebun di daerah penelitian tersebar tidak merata. Sebagian terdapat pada kelas lereng I dan II, dan sebagian lagi terdapat pada kelas lereng III dan IV di daerah penelitian. Sawah irigasi dengan luas area sebesar $1.71 \mathrm{~km}^{2}$ terdapat pada kelas kerawanan rendah, sedang dan tinggi. Umumnya penggunaan lahan ini terdapat pada kelas lereng I dan II. Kelas lereng III dan IV jarang dijumpai sebagai lahan pertanian dalam hal ini adalah sawah irigasi.

Sawah tadah hujan dengan luas area sebesar $0.23 \mathrm{~km}^{2}$, terdapat pada kelas kerawanan rendah, sedang dan tinggi. Kondisi tersebut terjadi karena sebagian besar penggunaan lahan untuk sawah tadah hujan terdapat pada kelas lereng landai hingga curam di daerah penelitian Tegalan dengan luas area sebesar $5.77 \mathrm{~km}^{2}$, terdapat pada kelas kerawanan rendah, sedang, tinggi dan sangat tinggi. Penggunaan lahan untuk tegalan di daerah penelitian tersebar tidak merata. Sebagian terdapat pada kelas lereng I dan II, dan sebagian lagi terdapat pada kelas lereng III dan IV di daerah penelitian. Rumput dengan luas area sebesar $1.06 \mathrm{~km}^{2}$, terdapat pada kelas kerawanan sangat rendah $\left(0.06 \mathrm{~km}^{2}\right)$, rendah $\left(0.56 \mathrm{~km}^{2}\right)$, sedang $\left(0.18 \mathrm{~km}^{2}\right)$ dan tinggi $\left(0.26 \mathrm{~km}^{2}\right)$.

\section{Kesimpulan}

Hasil penelitian menunjukkan tingkat kerawanan longsor di daerah penelitian terbagi kedalam 5 kelas kerawanan yaitu kelas kerawanan sangat rendah mencakup daerah seluas $0,6 \mathrm{~km}^{2}(0,19 \%)$, kelas kerawanan rendah mencakup daerah seluas 7,24 $\mathrm{km}^{2}(23,59 \%)$, kelas kerawanan sedang mencakup daerah seluas $7,16 \mathrm{~km}^{2}(23,33 \%)$, kelas kerawanan tinggi mencakup daerah seluas $12,35 \mathrm{~km}^{2}(40,24 \%)$, dan kelas kerawanan sangat tinggi mencakup daerah seluas $3,88 \mathrm{~km}^{2}(12,64 \%)$. Dari hasil penelitian tersebut dapat disimpulkan bahwa kelas kerawanan tinggi terhadap longsor mempunyai area paling luas di daerah penelitian. 
Perlu dilakukan tindakan pencegahan longsor di daerah penelitian agar tidak menimbulkan korban jiwa dan kerusakan lingkungan dalam jumlah besar. Upaya yang perlu dilakukan adalah adanya kesadaran dari masyarakat setempat dan pemerintah untuk tetap menjaga lingkungan terutama pada daerah dengan kelas kerawanan tinggi. Penelitian selanjutnya sebaiknya lebih memperhatikan aspek sosial dalam mengkaji longsor dan upaya mitigasi bencana akibat longsor di daerah penelitian.

\section{DAFTAR PUSTAKA}

Anbalagan, Rathinam, Rohan Kumar, Kalamegam Lakshmanan, Sujata Parida, and Sasidharan Neethu. 2015. "Landslide Hazard Zonation Mapping Using Frequency Ratio and Fuzzy Logic Approach, a Case Study of Lachung Valley, Sikkim." Geoenvironmental Disasters. https://doi.org/10.1186/s40677-014-0009-y.

Bappeda Kota Semarang. 2011. "Rencana Tata Ruang Wilayah Kota Semarang Tahun 2011-2031." Bappeda Kota Semarang.

BPS. 2016. "Kecamatan Banyumanik Dalam Angka 2016. Semarang: Kerjasama Bappeda Kota Semarang Dan Badan Pusat Statistik Kota Semarang.” 2016.

Dibyosaputro, S. 1999. "Longsor Lahan Di Daerah Kecamatan Samigaluh Kabupaten Kulonprogo Daerah Istimewa Yogyakarta.” Majalah Geografi Indonesia, 1999.

Hadmoko D.S., Lavigne F., Sartohadi J., Hadi P., Winaryo. 2010. "Landslide Hazard and Risk Assessment and Their Application in Risk Management and Landuse Planning in Eastern Flank of Menoreh Mountains." Nat Hazards, 623-42.

J, Suprapto. 2007. Teknik Sampling Untuk Survey Dan Eksperimen. Jakarta: Rineka Cipta.

Priyono K.D., Priyana Y., Priyono. 2006. “Analisis Tingkat Bahaya Longsor Tanah Di Kecamatan Banjarmangu Kabupaten Banjarnegara.” Forum Geografi 20 (2): 17589.

Thanden R, E., Sumadhirda H., Richards, P, W., Sutrisna K., Amin T.C. 2006. "Peta Geografi Lembar Magelang-Semarang Jawa, Skala 1:100.000." Peta. Bandung:Pusat Survei Geografi. 2006.

Trisnawati, D, N Najib, A S Hidayatullah, and ... 2020. "PENINGKATAN KAPASITAS SOSIAL DALAM MITIGASI BENCANA GERAKAN TANAH KELURAHAN METESEH KOTA SEMARANG.” Jurnal Pasopati.

Virgiawan, Dhimas Bagus. 2020. “ANCAMAN ERUPSI KAWAH IJEN TERHADAP MASYARAKAT LERENG IJEN (KABUPATEN BONDOWOSO)." ASANKA: Journal of Social Science And Education. https://doi.org/10.21154/asanka.v1i1.1945. 
